\title{
Probabilistic Duration Estimation Model for High-Rise Structural Work
}

\author{
Hyun-soo Lee"; Jae-won Shin²; Moonseo Park ${ }^{3}$; and Han-Guk Ryu ${ }^{4}$
}

\begin{abstract}
The duration of a construction project is a key factor to consider before starting a new project, as it can determine project success or failure. Despite the high level of uncertainty and risk involved in construction, current construction planning relies on traditional deterministic scheduling methods that cannot clearly ascertain the level of uncertainty involved in a project. This, subsequently, can prolong a project's duration, particularly when that project is high-rise structural work, which is not yet a common project type in Korea. Indeed, among construction processes, structural work is notable, as it is basically performed outdoors. Thus, no matter how precisely a schedule is developed, such projects can easily fail due to unexpected events that are beyond the planner's control, such as changes in weather conditions. Therefore, in this study, to cope with the uncertainties involved in high-rise building projects, a probabilistic duration estimation model is developed in which both weather conditions and work cycle time for unit work are considered to predict structural work duration. According to the proposed estimation model, weather variables are divided into two types: weather conditions that result in nonworking days and weather conditions that result in work productivity rate (WPR) change. Obtained from actual previous data, the WPR is used with relevant nonworking day weather conditions to modify the actual number of working days per calendar days. Furthermore, on the basis of previous research results, the cycle time of the unit work area is assumed to follow the $\beta$ probability distribution function. Thus, the probabilistic duration model is valid for $95 \%$ probability. Finally, a case study is conducted that confirms the model can be practically used to estimate more reliable and applicable probabilistic durations of structural work. Indeed, this model can assist schedulers and site workers by alerting them, at the beginning of a project, to project uncertainties that specifically pertain to structural work and the weather. Thus, the proposed model can enable personnel to easily amend, and increase the reliability of, the construction schedule at hand.
\end{abstract}

DOI: 10.1061/(ASCE)CO.1943-7862.0000105

CE Database subject headings: Simulation; Probability; Forecasting; Productivity; Buildings, high-rise; Construction management; Weather conditions.

\section{Introduction}

Compared to other industries, more time and effort are required to establish project plans in the construction industry. Moreover, when dealing with new projects such as high-rise buildings, the application of new technologies, lack of experience on the part of managers, and insufficient previous data make it more difficult to determine project durations. As well, when schedulers conclude that there are many uncontrollable risk factors in a construction project, they tend to set aside a relatively longer buffer time than

${ }^{1}$ Professor, Dept. of Architecture, Seoul National Univ., 39-430, San 56-1 Shinlim-dong, Kwanak-gu, Seoul 151-742, Korea. E-mail: hyunslee@snu.ac.kr

${ }^{2}$ Associate Research Engineer, Construction Strategy and Research Institute of Hanmiparsons, Co., Ltd., 9th Fl., City Air Tower Bldg., 159-9, Samgsung-dong, Kangnam-gu, Seoul 135-973, Korea. E-mail: jwshin@ hanmiparsons.com

${ }^{3}$ Associate Professor, Dept. of Architecture, Seoul National Univ., 39-433, San 56-1 Shinlim-dong, Kwanak-gu, Seoul 151-742, Korea (corresponding author). E-mail: mspark@snu.ac.kr

${ }^{4}$ Full-Time Lecturer, Changwon National Univ., 9 Sarim-dong, Changwon, Gyeongnam 641-773, Korea. E-mail: hgryu@changwon.ac.kr

Note. This manuscript was submitted on March 10, 2008; approved on June 18, 2009; published online on June 22, 2009. Discussion period open until May 1, 2010; separate discussions must be submitted for individual papers. This paper is part of the Journal of Construction Engineering and Management, Vol. 135, No. 12, December 1, 2009. CASCE, ISSN 0733-9364/2009/12-1289-1298/\$25.00. they would for normal projects. Thus, because such high-risk construction projects involve additional uncertainties that cannot be analyzed by normal scheduling methods, simulation methodologies have commonly been used.

In fact, after the development of CYCLONE by Halpin (1977), many attempts have been made to develop simulation tools particularly designed for construction projects. These include INSIGHT (Paulson 1978), MUD (Carr 1979), PRODUF (Ahuja and Nandakumar 1985), SIREN (Kavanagh 1985), SimCon (Chehayeb and AbouRizk 1998), PICCASO (Senior and Halpin 1998), ABC (Shi 1999), STROBOSCOPE (Martinez and Ioannou 1999), NETCOR (Wang and Demsetz 2000), and SPSS (Lee 2005). Although not all of these simulation tools are specifically used for project duration estimation, they all can reflect particular construction industry characteristics and can enhance the construction process. However, thus far, no research has been conducted that identifies how weather conditions specifically influence structural work duration, and no attempts have been made to develop a simulation model for estimating structural work duration of high-rise building projects.

Generally, a construction project can be divided into four main phases: site preparation, excavation, structural work (underground/aboveground), and finishing work. Because all four phases are critical, they must be planned and coordinated as precisely as possible; thus, the total time required to complete each phase is an important factor to consider during the planning phases of construction. For example, site preparation and excava- 
tion are impacted by site conditions, while excavation and underground structural work are affected by earth conditions. However, since site and earth conditions vary from project to project and are difficult to predict prior to site inspection, the standardization of these two phases is not only problematic but also meaningless. Contrastingly, the factors affecting structural work are related to construction methods; therefore, most of these factors are well known. Furthermore, structural work has the greatest effect on the total duration of a project.

Thus, this study focuses on the duration of high-rise structural work and proposes a simulative probabilistic model that can predict the probability of completing certain structural work on time. After construction method, weather conditions have the most significant influence on structural work duration; therefore, weather variables are important factors considered in the model. As well, this study specifically examines reinforced concrete structural work, as RC structures are the most widely used due to their cost advantages, despite the restrictions they impose on the speed of construction. Ultimately, the proposed probabilistic model can be applied not only to high-rise buildings but also to new projects, and it is an effective, alternative method for project duration estimation, as it provides schedulers with better organized knowledge.

This study is organized as follows.

1. Drawing from a literature review and in-depth interviews with scheduling experts from the top five construction companies in Korea, it was determined that the cycle time per unit work area according to the structural method, and the influence of weather, are the two main factors required to calculate structural work duration. Unit work area is a type of zone definition, which consists of a set of activities (e.g., structural work that includes installing form works, concrete pouring, concrete curing, etc.), and it is defined based on construction methods. It is established at the beginning of a project in which a single construction company conducts construction work using one construction method. In structural work, the unit work area is normally one floor; this is to avoid separate concrete pouring in maintaining structural resistance. However, when floors are too wide, nonseparate concrete pouring can cause cracking, so one floor is often divided into several zones.

2. Based on the literature review, the cycle time per unit work area was assumed to be a type of $\beta$ probability distribution, and the input data required to determine the $\beta$ distribution was obtained from in-depth interviews with scheduling experts.

3. The influence of weather was divided into two separate categories: weather variables that result in nonworking days and weather variables that affect productivity.

4. The probabilistic duration model was developed. This model estimates the duration of structural work by considering two factors: the cycle time per unit work area and the influence of weather.

5. The model was verified by applying it to a sample project.

\section{Literature Review}

Factors such as inclement weather, low productivity, and worker absence, among others, affect construction projects through the degree of uncertainty they introduce. Therefore, probabilistic methodologies have often been used to estimate construction project durations. For example, the program evaluation and re- view technique (PERT) considers probabilistic work duration using pessimistic, optimistic, and the most frequent time estimates. However, PERT only provides two results (68\% and 95\%) from the input data, and users are unable to choose specific options regarding project circumstances, such as adopted construction methods, starting date, and weather influences. As well, users are not given options regarding the needs of the parties involved, such as a client's request that the target finishing date be met.

Moreover, as computer technology has advanced, subsequent attempts have been made to develop simulation methods for calculating project duration. For instance, Carr (1979) introduced a model for uncertainty determination, which calculates an estimated time range for the completion of each activity. This model considers random variables that can affect work conditions, such as the productivity of crew and equipment, subsurface site conditions, the effectiveness of supervision, the dependability of subcontractors, and weather. These variables are separated into two categories: uncertainty independent of calendar date (INCAD) and uncertainty dependent on calendar date (DECAD). While weather falls under the latter category, all the other variables fall under the former. After obtaining an estimated duration for INCAD through Monte Carlo simulation, the actual duration for DECAD can be obtained. In this study, Carr (1979) established very specific relationships between DECAD variables such as precipitation, temperature, and work productivity. Nevertheless, determining the relationships between various variables and every activity in every construction method is time consuming and impractical.

In a later study, Lee (2005) proposed a simulation tool combined with the critical path method (CPM). After creating a schedule using commercial scheduling software and identifying the critical path network, this tool determines the probabilistic total duration by simulating the work that follows the critical path. This study is valuable, as the simulation method can be used for decision making in both the contracting and schedulemonitoring phases of construction. As well, the CPM is considered to be instrumental in saving time and effort when collecting data and determining the probability distribution. However, Lee's simulation method does not take individual construction processes into account. Therefore, as the schedule factors and special features of each construction process are not considered, the total duration reflects only those values inputted at each process of the critical path, which can result in unexpected schedule delays.

Furthermore, several researchers have used simulation systems to apply weather variables to construction project scheduling. For example, AbouRizk and Wales (1997) used a general regression neural network to account for the relationship between weather variables and earthwork productivity. This study investigated three weather variables: precipitation, daily maximum temperature, and daily minimum temperature. While this study assumed the productivity factor to be the ratio of achieved productivity to estimated productivity, it also demonstrated the impact weather variables have on a project schedule by calculating the durations for the same project according to different start dates, and by assuming a 93-day deadline. Yet, AbouRizk and Wales (1997) focused only on earthwork and investigated only three weather variables without explaining the predictable impact of other weather variables, or how the impact of weather variables varies from season to season. Additionally, in their research, different completion dates were predicted due to different start days without suggesting the probability of project completion.

On the other hand, the present study proposes a model for 
estimating project duration that considers the unique features of structural work as well as the main weather factors. As well, this simulation model can be used to estimate the project duration of unfamiliar projects, particularly high-rise structural work. This model is an efficient and well-organized method for estimating structural work duration of a project that considers seasonality and user options.

\section{Methodology}

In-depth interviews were conducted with scheduling experts from the top five construction companies in Korea. These interviews indicated that the two main determining factors of structural work duration are the cycle time per unit area and weather conditions. Cycle time is the initial factor used to calculate project duration because the total duration of a project is the sum of the work duration of each unit work area. Weather conditions, on the other hand, cannot be controlled, and it affects work conditions throughout the entire structural work. Moreover, other factors, such as site conditions, have less of an impact on structural work duration than they do on other types of construction work. Therefore, cycle time per unit area and weather are the two factors that must be used in structural work duration estimation.

\section{Probability Distribution for Cycle Time of Unit Area}

In order for the proposed simulation technique to function effectively, the duration of structural work per unit area should be treated as a type of probability distribution. This can be done in two ways. The probability distribution can be obtained from actual data or by assuming the probability distribution theoretically. The data can be obtained from any type of reference that shows work duration of every unit work area. The more precise these references are, the more reliable the estimate will be.

On one hand, the former approach-obtaining the probability distribution from actual data - can be used without the risk of choosing incorrect input data. As well, because this approach is based on actual data, a degree of reliability is automatically assured. However, because there is no specific goodness-of-fit test that will produce the "best" result, the user must choose a test at every planning stage at his or her own discretion. For example, Clemmens and Willenbrock (1978) used the chi-square test, while AbouRizk et al. (1994) used the Kolmogorov-Smirnov test. Yet, despite their extensive work, these researchers have failed to identify precisely why a particular distribution, which requires approval at every planning stage, should be used.

In the latter approach, assuming the probability distribution theoretically, a deterministic probability distribution must be used. Many researchers have attempted to determine the best probability distribution for constructing duration data, and they have found the $\beta$ distribution to be the most appropriate. According to MacCrimmon and Ryavec (1964) and Swanson and Pazer (1971), the distribution used to model the duration of a work task should be continuous over the entire range and must have a unique mode in the range, as well as two positive abscissa intercepts. Significantly, the $\beta$ probability distribution satisfies all of these conditions. It is a continuous distribution that belongs to the flexible family of distributions and is defined over a range. Both of its end points are fixed at exact locations. On the other hand, AbouRizk and Halpin (1992) demonstrated that most earthmoving construction operations can be described by the $\beta$ probability distribution. Farid and Koning (1994) subsequently proposed the $\beta$ probability distribution as the closest fit for modeling truck load and travel time distributions. Fente et al. (2000) have also reported that the $\beta$ distribution is suitable for modeling the durations of construction activities.

In the present study, to combine the merits of both the actual data and theory-based approaches, the probability distribution of unit work duration is assumed to follow the $\beta$ probability distribution, and the input data for the $\beta$ probability distribution is obtained from actual data as well as from expert opinion. A $\beta$ probability distribution requires data pertaining to four input parameters: (1) minimum duration per unit work area; (2) maximum duration per unit work area; and $\beta$ distribution shape parameters (3) $a$ and (4) $b$. Although parameters $a$ and $b$ are not time values, they are required in order to determine the shape of the $\beta$ probability distribution.

\section{Weather Conditions Affecting Structural Work}

Because construction projects are generally completed outdoors, this work is inevitably affected by weather conditions; however, in the actual field, only rainfall and adverse weather conditions result in nonworking days. In this study, the weather variables and their impact are not considered to a large extent with respect to work productivity. Instead, this research uses an estimate of the average number of nonworking days due to rain, which is based on past experience.

Given that the weather variables can be divided into two categories - those that result in nonworking days and those that affect the work productivity rate (WPR) — it was determined that the weather data should be classified as follows.

\section{Weather Data Resulting in Nonworking Days}

There are three variables that can cause nonworking days: temperature, precipitation, and wind. However, as shown in Table 1, the standards for nonworking days differ according to institute, construction company, and geographical region. Much research has been undertaken to standardize nonworking days; nevertheless, all of these studies have yielded different results.

Therefore, it is essentially meaningless to standardize nonworking days. Instead, this aspect of the weather data can be better determined by experts who can take company regulations, construction methods, and specific project characteristics into account.

\section{Weather Data Affecting Work Productivity Rate}

Based on the previous research and in-depth interviews with experts, average temperature, maximum temperature, minimum temperature, relative humidity, duration of sunshine, average wind velocity, precipitation, and the squares of all of these variables were selected as the weather variables affecting the structural WPR. Then, regression analysis was employed in a sample project to determine the relationships between the weather variables and the structural WPR. Actual weather data were obtained from the Korea Meteorological Administration (KMA; http:// www.kma.go.kr).

The WPR is determined as follows:

$$
P=\frac{D_{p}}{D_{a}}
$$

where $P=\mathrm{WPR} ; D_{p}=$ planned duration; and $D_{a}=$ actual duration.

A case in point is the construction of a 40-story building in downtown Seoul, Korea. The structural work of this building was conducted from September 2000 to August 2003 and used RC. 
Table 1. Suggested Standard of Nonworking Days

\begin{tabular}{|c|c|c|c|}
\hline & & Low temperature & High temperature \\
\hline \multirow[t]{8}{*}{ Temperature } & KNHC/AIK/KSCE/JSCE & Cold weather concrete at daily average below $4{ }^{\circ} \mathrm{C}$ & Hot weather concrete at daily average over $25^{\circ} \mathrm{C}$ \\
\hline & $\mathrm{KHC}$ & Daily average below $4{ }^{\circ} \mathrm{C}$ & Daily average over $35^{\circ} \mathrm{C}$ \\
\hline & Yang, G. Y. & Weekly temperature below $0^{\circ} \mathrm{C}$ & Weekly temperature over $25^{\circ} \mathrm{C}$ \\
\hline & Choi, I. H. & Daily average below $0^{\circ} \mathrm{C}$ & Daily average over $25^{\circ} \mathrm{C}$ \\
\hline & Jin, Y. S. & Daily average below $4{ }^{\circ} \mathrm{C}$ (structural work) & $50 \%$ of daily maximum over $35^{\circ} \mathrm{C}$ \\
\hline & $\mathrm{COE}$ & Daily maximum below $0^{\circ} \mathrm{C}$ & \\
\hline & ACI & Cold weather concrete at daily ave & ge below $4{ }^{\circ} \mathrm{C}$ \\
\hline & Choi, B. C. & Daily minimum below $2^{\circ} \mathrm{C}$ & \\
\hline \multirow[t]{5}{*}{ Precipitation } & KNHC & Over $10 \mathrm{~mm}$ a day & \\
\hline & RISH Act & Over $1 \mathrm{~mm}$ rain an hour/Over $1 \mathrm{~cm}$ & ff snow an hour \\
\hline & $\mathrm{COE}$ & Over $5 \mathrm{~mm}$ a day & \\
\hline & Yang, G. Y. & Over $10 \mathrm{~mm}$ of rain a day/Over 1 & of snow a day \\
\hline & Choi, B. C. & $50 \%$ of over $5 \mathrm{~mm}$ a day & \\
\hline \multirow[t]{2}{*}{ Wind } & RISH Act & Daily average over $10 \mathrm{~m} / \mathrm{s} /$ need eq & oment instant over $30 \mathrm{~m} / \mathrm{s}$ \\
\hline & Yang, G. Y. & Weekly maximum over $10 \mathrm{~m} / \mathrm{s}$ & \\
\hline
\end{tabular}

Note: $\mathrm{KNHC}=$ Korea National Housing Corporation; AIK=Architectural Institute of Korea; KSCE=Korean Society of Civil Engineering; JSCE=Japan Society of Civil Engineering; KHC=Korea Highway Corporation; COE=U.S. Army Corps of Engineers; and RISH Act=Regulations for Industrial Safety and Health Act.

From the actual structural work data, the WPR was calculated by dividing the estimated duration by the achieved duration. If the WPR is equal to or greater than 1 , the activity is said to be progressing well, but if the WPR is less than 1, the activity is said to be proceeding slower than expected.

Furthermore, the fact that free time does not compensate for lack of time is supported by the student syndrome: "People will start to fully apply themselves to a task just at the last possible moment before a deadline" and Parkinson Law: "Work expands so as to fill the time available for its completion." Therefore, from the data, only those days with a WPR less than 1 were chosen for further research, as it was assumed that a WPR greater than 1 is obtained due to abnormal work circumstances. The data on actual daily weather variables, including average temperature, maximum temperature, minimum temperature, relative humidity, precipitation, duration of sunshine, and average wind velocity were obtained from the KMA for each day.

While most of the previous studies on weather variables have dealt with an entire construction project, a few others have focused on specific project processes in treating the weather variables as a whole. However, it is evident that certain weather variables change with seasonal variations. For example, it can be assumed that the daily minimum temperature will not be as significant a factor in summer as in winter, whereas precipitation will most likely affect working conditions throughout the year without significant variation. Therefore, to take this variability into account, the weather data was divided into four groups: (1) March to May (spring); (2) June to August (summer); (3) September to November (autumn); and (4) December to February (winter). Even though there are no such definite seasonal divisions, these four groups are based on the generally accepted seasons in Seoul, Korea.

Then, to examine the relationships among these variables, regression analysis was used. Regression analysis is a statistical method for analyzing the functional relationships between variables. Essentially, this technique is used for three purposes: (1) to estimate the functional relationship between a dependent variable and independent variables; (2) to estimate and verify the influence of prior independent variables on the dependent variable; and (3) to estimate change in the dependent variable according to the functional relationship as the independent variables change. Two tests were subsequently used to identify whether or not the regression results were reliable: the t-test and the F-test. The t-test identifies whether a certain variable is reliable or not. To obtain the reliability, the absolute value of the $t$ value of the individual variables should be larger than 1.96 if there is a $95 \%$ probability of reliability, and 1.645 if there is a $90 \%$ probability of reliability. On the other hand, the F-test identifies whether the complete regression result is reliable or not. To ascertain the result's reliability, the $F$ value should be larger than the value suggested by the degree of freedom and the number of variables included.

Next, to sort the meaningful variables from the many independent variables so as to obtain a better regression function, the independent variables that lack reliability were repeatedly eliminated from the data lists. As a result, the important variables from the regression analysis results were identified; these are listed in Table 2 .

The modified $R$ square represents the degree of explanation of the result. Weather conditions might be the reason that, on certain days, the WPR is less than 1; this is observed with a degree of $30.5 \%$ for spring, $34.1 \%$ for summer, $47.3 \%$ for autumn, and $31.1 \%$ for winter. Furthermore, by using the method of linear interpolation, the $F$ values of the rejected area were found to be 2.522 for spring, 2.768 for summer, 2.606 for autumn, and 3.170 for winter. As shown in Table 2, the $F$ values of the regression analysis results were 8.666 for spring, 11.525 for summer, 11.111 for autumn, and 13.879 for winter. Thus, the four regression analysis results were judged to be highly reliable.

Furthermore, the relationship between the weather variables and the WPR was obtained. Out of 15 independent variables, eight variables were proven to be valid. The following Eqs. (2)-(5) show the mathematical relationships between the WPR and the weather variables:

$$
Y_{\mathrm{Sp}}=0.3036+0.0130 X_{2}-0.0249 X_{4}-9.41 E-05 X_{7}+0.0109 X_{8}
$$

$$
Y_{\mathrm{Sm}}=1.4309-0.0174 X_{1}-0.0129 X_{2}+9.036 E-05 X_{7}
$$




\begin{tabular}{|c|c|c|c|c|c|}
\hline \multirow[b]{2}{*}{ Season } & \multirow[b]{2}{*}{$\begin{array}{l}\text { Modified } \\
R \text {-square }\end{array}$} & \multirow[b]{2}{*}{$F$} & \multicolumn{3}{|c|}{ Independent variable } \\
\hline & & & Variable & $\begin{array}{l}\text { Unstandardized } \\
\text { coefficient }\end{array}$ & $t$ \\
\hline \multirow[t]{5}{*}{ Spring } & 0.305 & 8.666 & Constant & 0.3036 & 2.517 \\
\hline & & & Rel. hum. & 0.0130 & 3.406 \\
\hline & & & Ave. wind & -0.0249 & -1.965 \\
\hline & & & S. rel. hum. & $-9.41 \times 10^{-5}$ & -2.842 \\
\hline & & & S. dur. sun. & 0.0109 & 3.366 \\
\hline \multirow[t]{4}{*}{ Summer } & 0.341 & 11.525 & Constant & 1.4309 & 6.868 \\
\hline & & & Min. tem. & -0.0174 & -4.319 \\
\hline & & & Rel. hum. & -0.0129 & -1.845 \\
\hline & & & S. rel. hum. & $9.036 \times 10^{-5}$ & 1.965 \\
\hline \multirow[t]{5}{*}{ Autumn } & 0.473 & 11.111 & Constant & 1.1216 & 10.086 \\
\hline & & & Rel. hum. & -0.0105 & -3.103 \\
\hline & & & S. ave. tem. & -0.0004 & -5.065 \\
\hline & & & S. min. tem. & 0.0005 & 4.259 \\
\hline & & & S. rel. hum. & $7.810 \times 10^{-5}$ & 3.111 \\
\hline \multirow[t]{3}{*}{ Winter } & 0.311 & 13.879 & Constant & 0.6958 & 47.913 \\
\hline & & & Min. tem. & 0.0109 & 5.067 \\
\hline & & & Dur. sun. & 0.0159 & 3.846 \\
\hline
\end{tabular}

Note: Rel. hum.=relative humidity; Ave. wind=average wind velocity; S. rel. hum.=square of relative humidity; S. dur. sun.=square of duration of sunshine; Min. tem.=minimum temperature; S. ave. tem. $=$ square of average temperature; and Dur. sun. $=$ duration of sunshine.

$$
Y_{\mathrm{Fl}}=1.1216-0.0105 X_{2}-0.0004 X_{5}+0.0005 X_{6}+7.810 E-05 X_{7}
$$

$$
Y_{\mathrm{Wn}}=0.6958+0.0109 X_{1}+0.0159 X_{3}
$$

where $Y_{\mathrm{Sp}}=\mathrm{WPR}$ in spring; $Y_{\mathrm{Sm}}=\mathrm{WPR}$ in summer; $Y_{\mathrm{Fl}}=\mathrm{WPR}$ in fall; $Y_{\mathrm{Wn}}=\mathrm{WPR}$ in winter; $X_{1}=$ minimum temperature; $X_{2}$ = relative humidity; $X_{3}=$ duration of sunshine; $X_{4}=$ average wind velocity; $X_{5}=$ square of average; $X_{6}=$ temperature; $X_{7}=$ square of minimum temperature; and $X_{8}=$ square of relative humidity.

It should be noted that precipitation, a factor influential on the WPR, is not included in this result because if the precipitation is larger than a certain amount, work cannot proceed. In this case, the day is regarded as a nonworking day. Contrastingly, a smaller amount of precipitation has no serious effect on the WPR.

The minimum temperature, relative humidity, and square of relative humidity are included in more than two equations. They have varying effects on the WPR which, in turn, is dependent on the season. For example, the coefficient of relative humidity is +0.0130 in spring, whereas it is -0.0129 in summer and -0.0105 in autumn. This implies that the WPR decreases in summer when the humidity is high, and in autumn when the humidity increases; however, in spring when the air is dry, high humidity helps workers achieve a better WPR. Furthermore, in cold winters when temperatures are lower, the higher minimum temperature in the morning has a positive effect on the WPR but has the opposite effect in summer. These relationships between the weather variables and the WPR are intuitive as based on our daily lives; thus, it is important to distinguish the variables that have a more significant effect and identify the numerical relationships for precise application.

\section{Estimating Model for Structural Work Duration}

An estimating model was developed that considers the two main factors influencing structural work duration: the cycle time per unit work area and weather variables. The logical model process is illustrated in Fig. 1. This model process consists of four phases: (1) establishing the unit work area; (2) identifying the four parameters for the $\beta$ probability distribution; (3) running the simulation; and (4) matching the weather variables.

\section{Phase 1: Establishing Unit Work Area}

The construction methods used to address structural work, project size, and site conditions are clearly defined in the preparatory phases of a construction project. The unit work area is established based on this information. The unit work area can consist of either one floor or separate zones. The position and the order of the unit work area are determined by taking the features of the project, such as project type, size, location, adopted construction method, etc., into consideration.

\section{Phase 2: Identifying Four Parameters for the Beta Probability Distribution}

As previously discussed, it is assumed that the duration for the unit work follows a $\beta$ probability distribution. Therefore, the four parameters of the $\beta$ probability distribution-maximum and minimum duration times and $\beta$-shaped parameters $a$ and $b$-must be determined. The maximum and minimum duration times can be obtained from previous data and expert opinion.

Unlike the maximum and minimum durations, the $\beta$-shaped parameters $a$ and $b$ are not real values of work; therefore, they are estimated using a procedure for matching the $\beta$ distributions to the activity times. In this procedure, a public domain micro- 


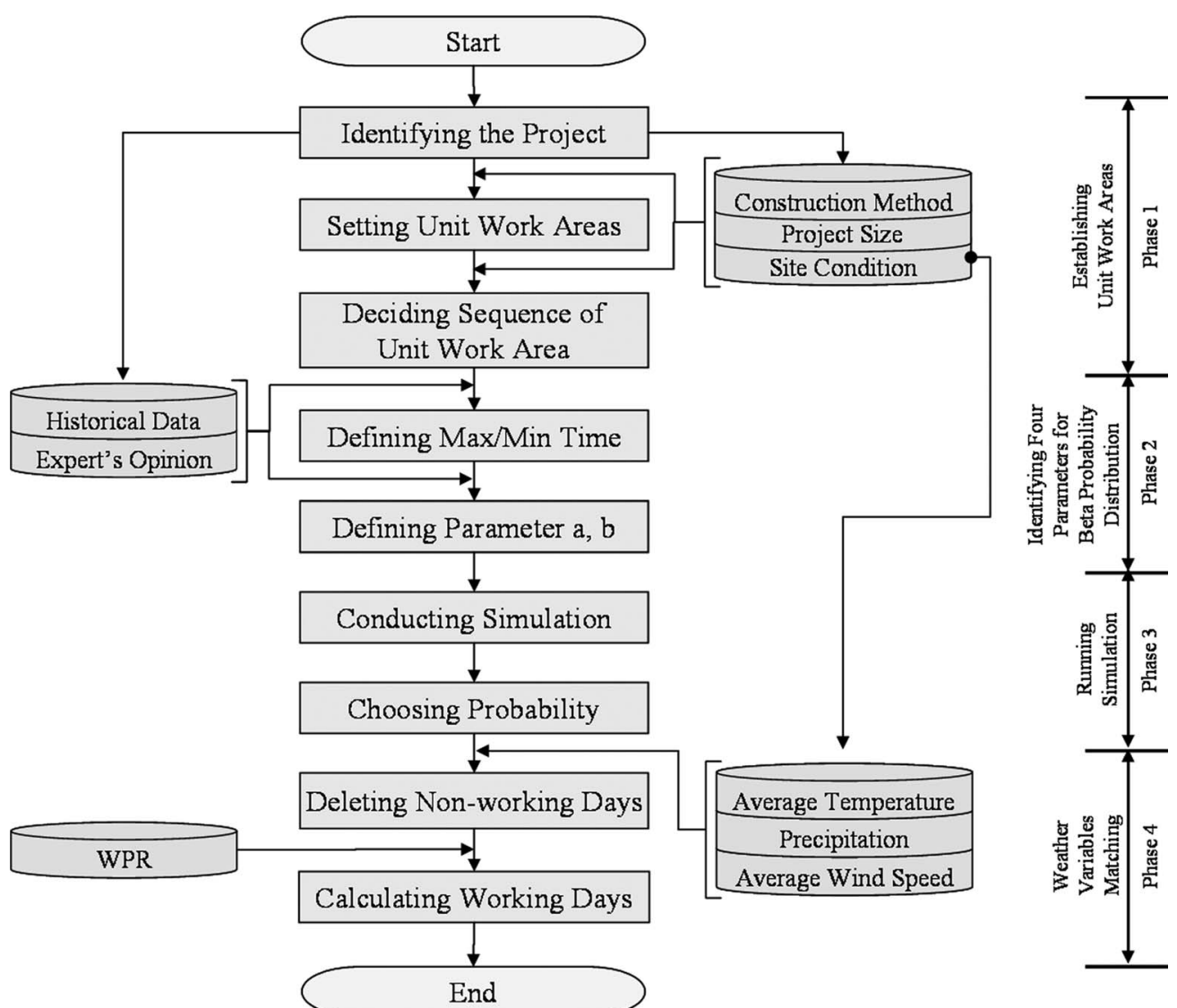

Fig. 1. Logic flow of the forecasting model

computer-based software system, named VIBES, is implemented (AbouRizk et al. 1991). To determine the $\beta$-shaped parameters of a unique $\beta$ probability distribution, VIBES uses a combination of five activity-duration characteristics, two of which must be the maximum and minimum durations. The possible characteristic combinations are the maximum and minimum activity durations with either the mean and standard deviation, the mean and the mode, the mode and standard deviation, two selected percentiles, or the mode and a selected percentile. Several researchers (Alpert and Raiffa 1969; Lichtenstein et al. 1977; Schexnayder et al. 2005) have revealed that subjective estimates of certain percentiles of a population are reasonably accurate, especially the 75 th percentile. Therefore, the mode time and the 75 th percentile time value are used to identify the $\beta$-shaped parameters $a$ and $b$.

Considering that the $\beta$-shaped parameters $a$ and $b$ are determined using the given time of the mode and the time value of the 75 th percentile, the maximum duration, minimum duration, mode, and the 75th percentile time value can be used as input data for the $\beta$ probability distribution. Table 3 shows the method by which the four parameter values are determined.
However, in the case that there is no previous data, such as data on high-tech construction methods, the four parameters should be obtained from expert opinion. An expert is either a skilled scheduler, experienced construction manager, or any team member familiar with the project type or the construction methods deployed. According to Wilson et al. (1982), an expert can easily and accurately estimate the endpoints of an activity duration distribution based on his or her familiarity with technological knowledge pertaining to the target activity. Thus, when there is an absence of relevant previous data, expert opinion plays a significant role in setting the minimum time. And if there is a statistically valid amount of sufficient data, all of the parameters can be obtained from previous project data, except for the minimum time, which is determined by experts. As well, even if the amount of data are not statistically valid, if it is valid from an expert's perspective, all of the parameters, excepting the minimum time, can still be easily obtained from previous data.

Table 3. Source of Four Parameters

\begin{tabular}{lccc}
\hline & & & Number of data $\leqslant 30$ \\
\cline { 3 - 4 } Parameter & Number of data $\geqslant 30$ & $N \leqslant 5$ & $5 \leqslant N \leqslant 30$ \\
\hline Minimum time & Expert's opinion & Expert's opinion & Expert's opinion \\
Maximum time & Previous data & Expert's opinion & Expert's opinion/previous data \\
Mode time & Previous data & Expert's opinion & Previous data \\
75th percentile value & Previous data & Expert's opinion & Previous data \\
\hline
\end{tabular}




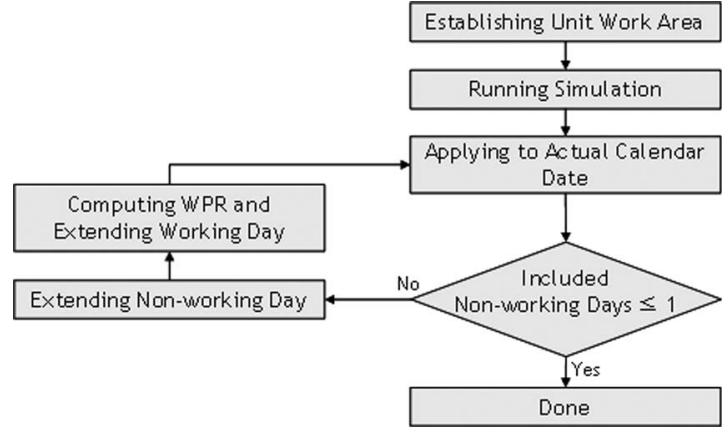

Fig. 2. Repetitive application of weather elements

\section{Phase 3: Running the Simulation}

There are many simulation techniques that can be used to predict future situations. Among the various techniques, Monte Carlo simulation estimates the variables broadly, establishes the probability distribution of the variables, generates a random number within the probability distribution, and determines the resulting distribution. This method uses an iterative operation that ensures higher reliability than other techniques. The only disadvantage of Monte Carlo simulation is that the repetitiveness of the iterative operation is time consuming. In the present study, Crystal ball 7.0 from Decisioneering, Inc. was used to manage the Monte Carlo simulation. Since Crystal ball 7.0 is based on Microsoft Excel, it is superior to the other programs in terms of applicability. Meanwhile, burdensome jobs, such as inputting data and repetitive data treatment, can be completed with Macro VBA in Excel.

After determining the unit work area, the probabilistic duration for the unit work area is assumed with a $\beta$ distribution. Then, the probability distribution is applied to all of the work areas, and a critical path is determined by schedulers considering characteristics of each unit work area. The total work duration is calculated by adding up the durations of all the unit work areas which are on a critical path. At this phase, the probability of the project's completion is chosen.

\section{Phase 4: Matching Weather Variables}

Subsequent to obtaining the total duration of the structural work, the weather variables are considered. The process of matching weather variables is conducted as follows.

1. If the total duration of the structural work is estimated, a start date is determined, and the duration of the structural work is applied to that actual calendar date.

2. After predicting the weather conditions during the actual working days, the number of nonworking days is calculated and the completion date is extended.

3. If the nonworking days are included in the total work schedule, the WPR of all of the working days are computed, and the extended days are added to the actual calendar date.

4. Steps (1)-(3) are repeated until no nonworking days are included in the actual working days.

Fig. 2 illustrates the weather matching process.

\section{Case Study}

To verify the model, it was applied to an actual case. However, due to time constraints, it was applied to a real-life, completed, not ongoing, construction project. All of the experimental condi- tions were conformed exactly to the actual ones, with the exception that in the weather prediction model, actual weather information was used.

As previously mentioned, the sample case was a high-rise construction project in Seoul, Korea, in which the structural work was performed using RC from November 2001 to February 2003. This project consisted of three buildings, and the time taken to complete all three buildings exceeded the planned duration. In this case study, the tallest, 38-floor Building A, was selected because it exhibits the greatest difference between actual work days and planned days. As well, the same company was used not only to avoid possible discrepancies, but also to apply the same relationships between the WPR, the weather variables, and the company's weather criteria. It should also be noted that each construction company has a distinct reputation and a unique approach to defining a nonworking day.

The proposed model was used to estimate the total duration of this project.

\section{Phase 1: Establishing Unit Work Area of Case Project}

Assuming that the unit work area was established in the actual project with adequate consideration during the preparatory stages of construction, the unit work area was determined by analyzing the actual data of the case project. Accordingly, a single floor was considered to be the unit work area. As well, in this construction project, three types of floors were built: the first five floors, the typical floor, and the transfer floor. The transfer floor has a different floor plan than a typical floor. This is either due to necessity, a construction method limitation, or aesthetic reasons.

\section{Phase 2: Identifying Four Parameters for the Case Project's Beta Probability Distribution}

Based on the previous data and the opinion of the expert in charge of scheduling the actual project, the maximum and minimum durations for a typical floor were identified as 11 and 3 days, respectively. In this phase, the previous data used were the structural work duration of each floor from the same company's other two high-rise building projects. In order to determine the $\beta$-shaped parameters $a$ and $b$, the mode time and the 75th percentile time value were identified as 5 days and 6 days, respectively. Then, using this data and VIBES, the $\beta$-shaped parameters $a$ and $b$ were set to 3.458 and 8.375 , respectively.

Finally, using the maximum and minimum durations and the $\beta$-shaped parameters $a$ and $b$, the $\beta$ probability distribution of a typical floor was obtained as shown in Fig. 3.

\section{Phase 3: Running Simulation of Case Project}

After establishing the probability distribution for the typical floor, first 5 floors, and transfer floor, which are on a critical path, and forming their sequence, the total duration was calculated as shown in Fig. 4. Fig. 4 shows the 80th percentile time value of Building A.

\section{Phase 4: Matching Weather Variables of Case Project}

As shown in Fig. 4, the total duration of the case project was 341 days. In this company, a nonworking day is defined as resulting from the following conditions: (1) the daily average temperature is below $-2{ }^{\circ} \mathrm{C}$; (2) the daily average wind velocity is greater than $10 \mathrm{~m} / \mathrm{s}$; and (3) the daily precipitation is over $10 \mathrm{~mm}$. The actual 


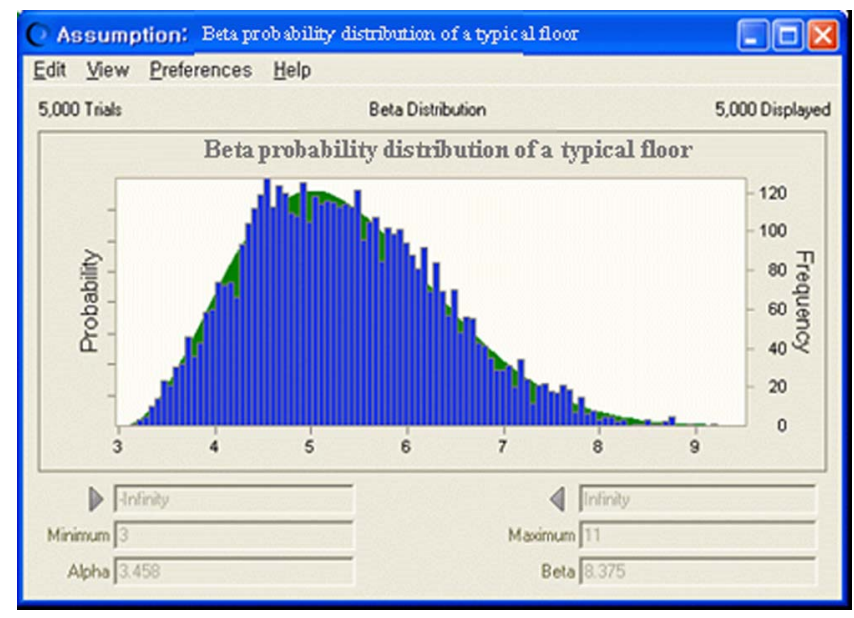

Fig. 3. Probability distribution for the duration of typical floor

start date of this project was November 25, 2001. After deleting all of the nonworking days, since no nonworking day was included in the duration, January 24, 2003 was estimated to be the completion date. The difference between the 425 calendar days and the 341 working days shows that 84 nonworking days were included in the total duration. Fig. 5 shows the $80 \%$ probability distribution of the final estimate duration for Building A.

Although a probability of $80 \%$ was used for the example, by applying the same procedure to Buildings $\mathrm{B}$ and $\mathrm{C}$, the completion duration probability values of $80 \%$ and $90 \%$ were obtained, respectively, as shown in Fig. 6. Furthermore, the different values for the actual working days - the actual planned duration of the project and the duration estimate yielded with the proposed model-are shown in Table 4.

The difference between the planned duration and the actual work duration was 45 days for Building A, 36 days for Building $\mathrm{B}$, and 18 days for Building $\mathrm{C}$. However, compared with the actual work duration, the proposed model predicted, with the $80 \%$ probability value, 14 days less for Building A, 10 days less for Building B, and 6 days less for Building C. With the $90 \%$ probability value, the model predicted 4 days more for Building A, 1 day more for Building B, and 14 days more for Building C. Thus,

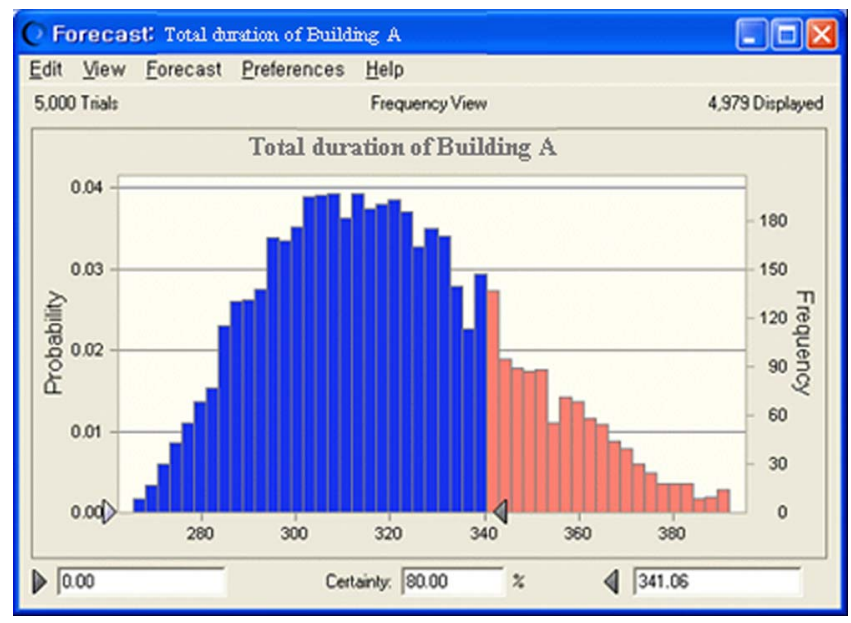

Fig. 4. Probability distribution of building a total duration

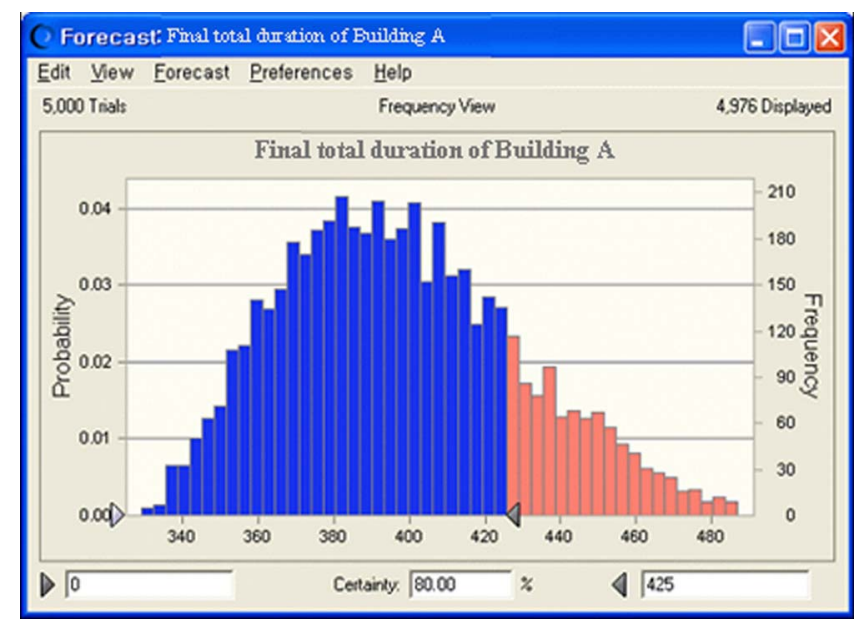

Fig. 5. Final forecasted duration of Building A-80

it can be concluded that the probabilistic duration model provides a more accurate prediction of the duration than the traditional definitive method.

To further illustrate the advantages of the proposed model, the probabilistic method PERT was used and then compared with the probabilistic duration model. Using a probabilistic approach and a suggested range of duration, PERT is a good alternative to the definitive CPM. However, the results of PERT are prohibitively vague, which prevents users from obtaining the expected probability. In contrast, the proposed probabilistic estimating model can yield more accurate results according to users' choices.

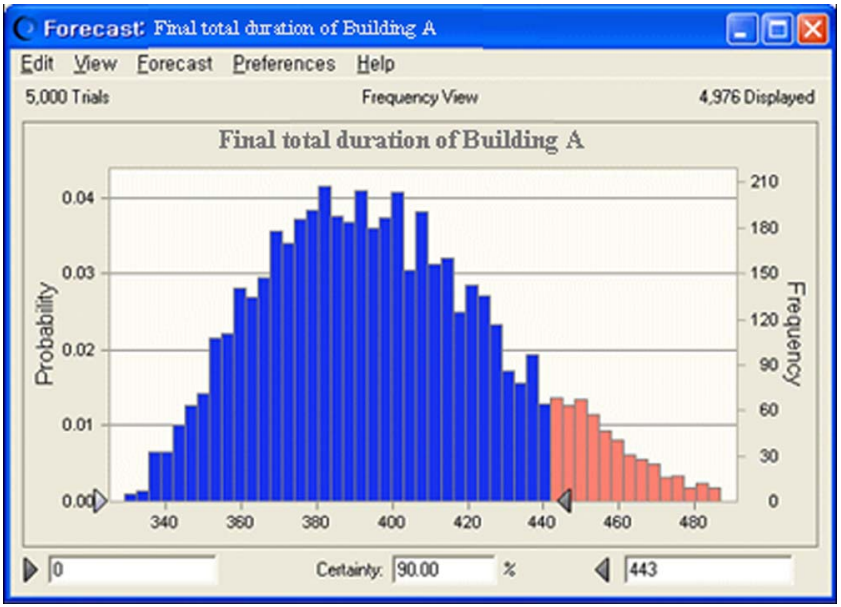

Fig. 6. Final forecasted duration of Building A-90

Table 4. Comparison of the Results

\begin{tabular}{lccc}
\hline Building & A & B & C \\
\hline Total floors & 37 & 29 & 26 \\
Actual duration & 439 & 369 & 330 \\
Planned duration & $394(-45)^{\mathrm{a}}$ & $333(-36)$ & $312(-18)$ \\
Forecasted 80\% duration & $425(-14)$ & $35(-10)$ & $336(6)$ \\
Forecasted 90\% duration & $443(4)$ & $370(1)$ & $344(14)$
\end{tabular}

${ }^{\mathrm{a}}$ Difference between actual duration and planned duration of the case project. 
Using the PERT technique, the expected average durations for Buildings A, B, and C were 336, 287, and 296 days, respectively, with a SD of 1.33. According to the empirical rule, $68 \%$ of the measurements will fall within one standard deviation of the mean, while $95 \%$ will fall within two standard deviations of the mean. Therefore, for the $68 \%$ probability value, the expected total duration for Buildings A, B, and $\mathrm{C}$ was 369, 308, and 315 days, respectively, and for the $95 \%$ probability value, the durations were 403, 330, and 333 days, respectively. In this case, PERT yields better results than the CPM and also provides alternative durations. However, PERT can predict only two fixed percentiles, the $68 \%$ and $95 \%$ measurements, and the relationships with the standard deviation are only assumptions based on the empirical rule.

Thus, although this case indicates that the PERT method is preferable to the CPM method, the proposed model is superior to PERT in terms of reliability and applicability. The proposed estimating model predicts project duration by determining probability and helps schedulers predict the possibility of project completion. At the same time, the proposed model assists schedulers in developing a more reasonable schedule on a more reliable basis.

\section{Conclusions}

To address the limitations of traditional deterministic duration estimating techniques, this study proposed a probabilistic model for predicting structural work duration. This model estimates structural work duration based on the probability distribution of the unit work area, revises its estimates by considering nonworking conditions and the WPR equation, and finally provides the total duration in the form of a probability. Furthermore, unlike previous studies, this research examined two predominant schedule-affecting factors that are specifically pertinent to structural work: (1) the cycle time per unit work area and (2) weather variables. Through an analysis of the relationship between the WPR and weather variables, it was found that weather variables greatly influence the WPR and that certain variables impact WPR more than others. As well, this analysis highlighted that weather variables vary significantly based on seasonality.

The findings of this study indicate that the proposed model has various advantages. First, although it was tested with RC, this model can be applied to other construction works, and it can be used effectively in the contractual and initial phases of construction projects. Additionally, this flexible model can be used to generate more reliable estimates, even for new high-tech construction methods for which there is a lack of previous data. This feature makes the proposed model particularly useful when the construction method changes during a project. As well, this model can easily amend schedules with minimal information on new methods of construction and/or weather data. Furthermore, this interactive model can also consider the user's risk taking policy; this assists the model in determining the appropriate probability value for total duration.

Finally, a case study confirmed the validity of the proposed model. The final duration estimate was obtained with $80 \%$ and $90 \%$ probability, both values indicating a more accurate result, with regards to actual duration, than the originally planned duration. In this research, $90 \%$ probability produced more accurate estimates than $80 \%$ probability; however, altering project conditions could change this result. Therefore, this model must be further tested to determine how it functions in different contexts. Moreover, this model must be used iteratively in actual projects so that more data can be accumulated, which will enable users to determine which value to choose for the four parameters of the $\beta$ distribution.

\section{Acknowledgments}

The writers acknowledge the support of the Korean Ministry of Construction and Transportation, through the Research Project No. 05 CIT D05-01.

\section{References}

AbouRizk, S. M., and Halpin, D. W. (1992). "Statistical properties of construction duration data." J. Constr. Eng. Manage., 118(3), 525543.

AbouRizk, S. M., Halpin, D. W., and Wilson, J. R. (1991). "Visual interactive fitting of beta distributions." J. Constr. Eng. Manage., 117(4), 589-605.

AbouRizk, S. M., Halpin, D. W., and Wilson, J. R. (1994). "Fitting beta distributions based on sample data." J. Constr. Eng. Manage., 120(2), 288-305.

AbouRizk, S. M., and Wales, R. J. (1997). "Combined discrete-event/ continuous simulation for project planning." J. Constr. Eng. Manage., 123(1), 11-20.

Ahuja, H. N., and Nandakumar, V. (1985). "Simulation model to forecast project completion time." J. Constr. Eng. Manage., 111(4), 325342.

Alpert, M., and Raiffa, H. (1969). "A progress report on the training of probability assessors." Judgement under uncertainty: Heuristics and biases, Cambridge University Press, Cambridge, U.K., 294-305.

Carr, R. I. (1979). "Simulation of construction project duration." J. Constr. Div., 105(CO2), 117-128.

Chehayeb, N. N., and AbouRizk, S. M. (1998). "Simulation-based scheduling with continuous activity relationships." J. Constr. Eng. Manage., 124(2), 107-115.

Clemmens, J. P., and Willenbrock, J. H. (1978). "The SCRAPESIM computer simulation.” J. Constr. Eng. Manage., 104(4), 419-435.

Farid, F., and Koning, T. L. (1994). "Simulation verifies queuing program for selecting loader-truck fleets." J. Constr. Eng. Manage., 120(2), 386-404

Fente, J., Schexnayder, C., and Knutson, K. (2000). "Defining a probability distribution function for construction simulation." J. Constr. Eng. Manage., 126(3), 234-241.

Halpin, D. W. (1977). "CYCLONE-Method for modeling job site processes." J. Constr. Div., 103(CO3), 489-499.

Kavanagh, D. P. (1985). "SIREN: A repetitive construction simulation model." J. Constr. Eng. Manage., 111(3), 308-323.

Lee, D. E. (2005). "Probability of project completion using stochastic project scheduling simulation." J. Constr. Eng. Manage., 131(3), 310-318.

Lichtenstein, S., Fischhoff, B., and Phillips, L. D. (1977). "Calibration of probabilities: The state of the art to 1980." Judgement under uncertainty: Heuristics and biases, Cambridge University Press, Cambridge, U.K., 306-344.

Martinez, J. C., and Ioannou, P. G. (1999). "General-purpose systems for effective construction simulation.” J. Constr. Eng. Manage., 125(4), 265-276.

MacCrimmon, K. R., and Ryavec, C. A. (1964). "An analytical study of the PERT assumptions." Oper. Res., 12(1), 12-37.

Paulson, B. C. (1978). "Interactive graphics for simulating construction operations." J. Constr. Eng. Manage., 104(1), 69-76.

Schexnayder, C., Knutson, K., and Fente, J. (2005). "Describing a beta probability distribution function for construction simulation." J. Constr. Eng. Manage., 131(2), 221-229.

Senior, B. A., and Halpin, D. W. (1998). "Simplified simulation sys- 
tem for construction projects." J. Constr. Eng. Manage., 124(1), 7281.

Shi, J. J. (1999). “Activity-based construction (ABC) modeling and simulation method." J. Constr. Eng. Manage., 125(5), 354-360.

Swanson, L. A., and Pazer, H. L. (1971). "Implications of the underlying assumptions of PERT.” Decision Sci., 2, 461-480.
Wang, W. C., and Demsetz, L. A. (2000). "Model for evaluating networks under correlated uncertainty-NETCOR." J. Constr. Eng. Manage., 126(6), 458-466.

Wilson, J. R., Vaughan, D. K., Naylor, E., and Voss, R. G. (1982).

"Analysis of space shuttle ground operations." Simulation, 38(6), 187-203. 